IRA-International Journal of Management \& Social Sciences

ISSN 2455-2267; Vol.07, Issue 02 (2017)

Pg. no. 172-177

Institute of Research Advances

http://research-advances.org/index.php/RAJMSS

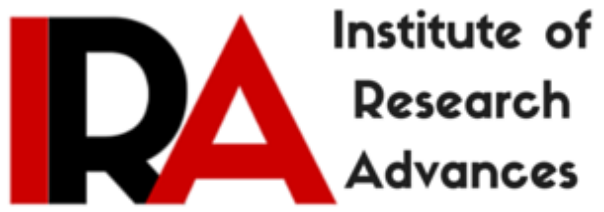

\title{
Recognizing Communication Skills as a Professional Tool
}

\author{
Sunita Mohapatra \\ M. A (English); MBA (HR) \\ Assistant Professor, USBM Bhubaneswar, \\ Khurda - 751024, India.
}

Type of Review: Peer Reviewed.

DOI: http://dx.doi.org/10.21013/jmss.v7.n2.p6

\section{How to cite this paper:}

Mohapatra, S. (2017). Recognizing Communication Skills as a Professional Tool. IRA-

International Journal of Management \& Social Sciences (ISSN 2455-2267), 7(2), 172-177. doi:http://dx.doi.org/10.21013/jmss.v7.n2.p6

(C) Institute of Research Advances

\section{(c)) EY-NO}

This work is licensed under a Creative Commons Attribution-Non Commercial 4.0 International License subject to proper citation to the publication source of the work.

Disclaimer: The scholarly papers as reviewed and published by the Institute of Research Advances (IRA) are the views and opinions of their respective authors and are not the views or opinions of the IRA. The IRA disclaims of any harm or loss caused due to the published content to any party. 


\section{ABSTRACT}

Today's corporate world has become an ultimate destination for every youth. Getting success in the profession is not only a dream but a determination for them. The reason behind this is rigorous competition and talents which are no less in the society. These jobs give high profile platform to employees. This also provides immediate growth opportunity and exposure to them so that the employees sharpen their skills and inherent qualities. Adequate knowledge about techniques and field related skills are must, but they are not sufficient. If an individual wants to sustain in this era he/she has to have strong communication skills. The increasing pressures and professional challenges widen the role of managers. Professional authorities in Multi National Companies always expect that their employees should possess efficiency and good communication skills. This paper highlights how communication skills take importance in making a professional successful in his/her career. Through this study it is shown that companies having employees with strong communication skills are more successful and their work environments are destinations for job seekers.

Key Words: Corporate world, Communication skills, Professional challenge, Manager, work environment.

\section{Introduction}

'Communication' means imparting or sharing knowledge between two or more individuals. It is a process of exchanging human thoughts, values and ideas to people on the other side. We find it as a life-blood of any business organization. Since we are social animals, it becomes a matter of impossibility to think of living without communication.

In this regard, I would like to quote "Whosoever is delighted in solitude, is either a wild beast or a god."Aristotle. It is about more than just exchanging information. It's about understanding the emotion and intentions of a speaker behind the information. For the present scenario of business, not communication but effective communication turns as the standard means of making an organization lead or trail. To an employer, good communication skills are essential. In fact, employers consistently rank good communication skills at the top of the list for potential employees.

\section{Literature review}

In the 1940s, systems theory achieves insights into communication (Heath \& Bryant, 2000). Especially in major organizational communications, systems theory explains how and why people form groups, each of these is a system as well as an element of a larger system. The focus of organizational communication is on the whole system, rather than on parts of the system (Katz \& Kahn, 1996). "Communication serves as the basis for control and coordination in organizations; it also provides information essential to effective completion of the organizational mission" (Poole, 1978, p. 493). But, what "exactly" is communication? In layman's terms, communication is the interchange of information between two or more persons. Farace, Monge and Russell (1977) define communication as the interchange ofsigns or symbols that are shared by the people involved, and which evoke quite similar symbolic relationships in each of them. Organizational communication goes a bit further. Organizational communication is "both similar to and distinct from other types of communication" (Shockley-Zalabak, 1999, p. 28). It is more than the daily interactions of individuals within organizations; it is the process of creating and shaping organisational events (Shockley-Zalabak, 1999).According to Hybels and Weaver (1995), the communication process is made up of various elements like sender-receiver, encoding-decoding messages, channels, noise, feedback, and setting. Several models have been developed which details the different essentials of the communication process. Richard Fiordo (1990) diagrams a good model of the educational communication process. These interpersonal models of communication takes into consider the different elements as indicated by Hybels and Weaver (1995) but with more detail. 


\section{Methods}

\subsection{Research Objectives}

In the presence of vast research and studies on communication, it is expected that communication skills (mainly verbal; though nonverbal means is another segment of my study) is to be understood by everybody in general that it is a major professional tool. The following objectives are set:

To explore the communication skills as a major tool of getting organizational success.

$>$ To show that a strong communication skill gives exposure to professionals.

To give readers a strong enthusiasm of being able to communicate themselves as situation and audience demands.

\subsection{Research Design}

This work is designed to be an empirical one. It is planned to collect data from the employees of 4 MNCs of Insurance sector and 2 products based large scale industries. The questionnaire was set after reviewing literature and it has served the objective of elucidating the fact that without proper communication system the business firms are not successful. Again, the industries or the business firm who are strong in communication have stood upon extreme success and most importantly can maintain a soothing work environment and culture there.

The target was prepared to collect data from 300 employees of both the companies who have been working there for more than 3 years and some have changed their previous places and joined here. The collected data was planned to make it informative after analyzing it.

\subsection{Data collection and Analysis}

The data was collected through a set questionnaire during face to face and self administered interviews. Some parts of the data were collected by mailing questionnaires to the known professionals working in MNCs or large scale industries.

Secondary data has been collected from company websites and journals of this kind.

During analysis views were collected from a group of 7 members'. After selection and rejection process a final conclusion was drawn out of the 4 sample MNCs, 3 MNCs did their excellent in each field. These were organizations most candidates look for and the rest was an established company but failed to attract talented employees even could not retain them for more than 1 year.

And about the 2 large scale industries, both were in growing stage. They were following the foot print of such smart industries that not only focus on money maximization but also demand a social status as well as reputation. Their employees were smart, proactive and full of enthusiasm towards communication. They believe on working in a comfortable work environment and nurturing leadership could give that. Effective Communication was the only 'mantra' that made all these possible.

\section{Discussion}

In the 21st century, business has become more intricate than ever, in companies that conduct operations at several locations, or even wide-reaching. In this environment, communication skills have become principal and employers are more and more looking for those who can express or communicate well. By this they can function in complex business environments. Communication skills are basic to the effective functioning of any organizational works. As we know, communication skills are the combination of 4 skills, such as: 


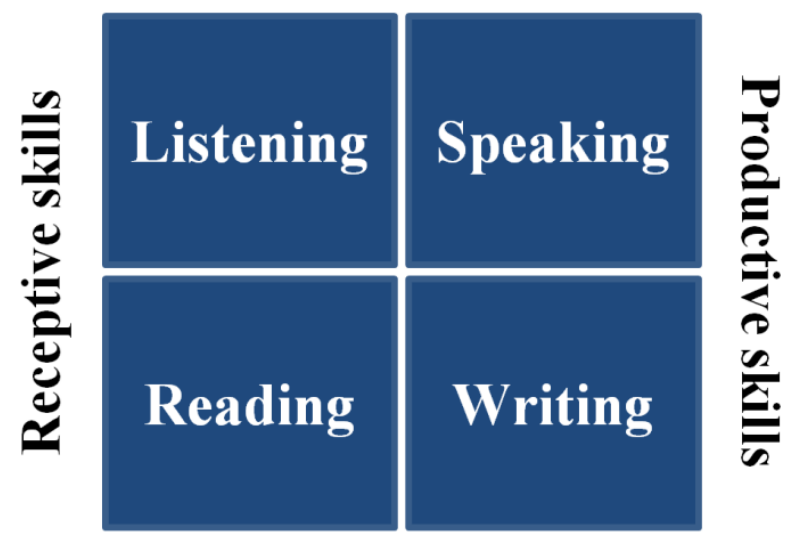

Fig.1. Components of Communication Skills

We make every effort to improve communication more and more effective. This is required in any medium like writing, speaking, discussion or arguments or public speaking in the world so competitive. The two remarkable traits of a good professional are good communication skills and a good dress sense, apart from the appearance and voice. When we say communication, we include the words, language, sentence and adequate body language to carry it. This skill is important to professionals who deal with humans, attend meetings, deliver public lectures and social gatherings etc. A person's magnificent deliverance of communication can leave a lasting impression before others. It adds value to his/her personality and enhances professional dignity as well.

\section{Managerial implications}

Communication is an essence of business. If employees know their position in the work place, and they feel comfortable in that environment, they will be motivated to do good work. Effective Communication Skills are not just good for the life of the company, but they help you understand how everything is going within the company. It gives you some real-world "data," to speak. A manager does many functions upon which a team's result depends. And for doing so he takes use of the most powerful tool of 'COMMUNICATION'. To name some of its roles as follows: 


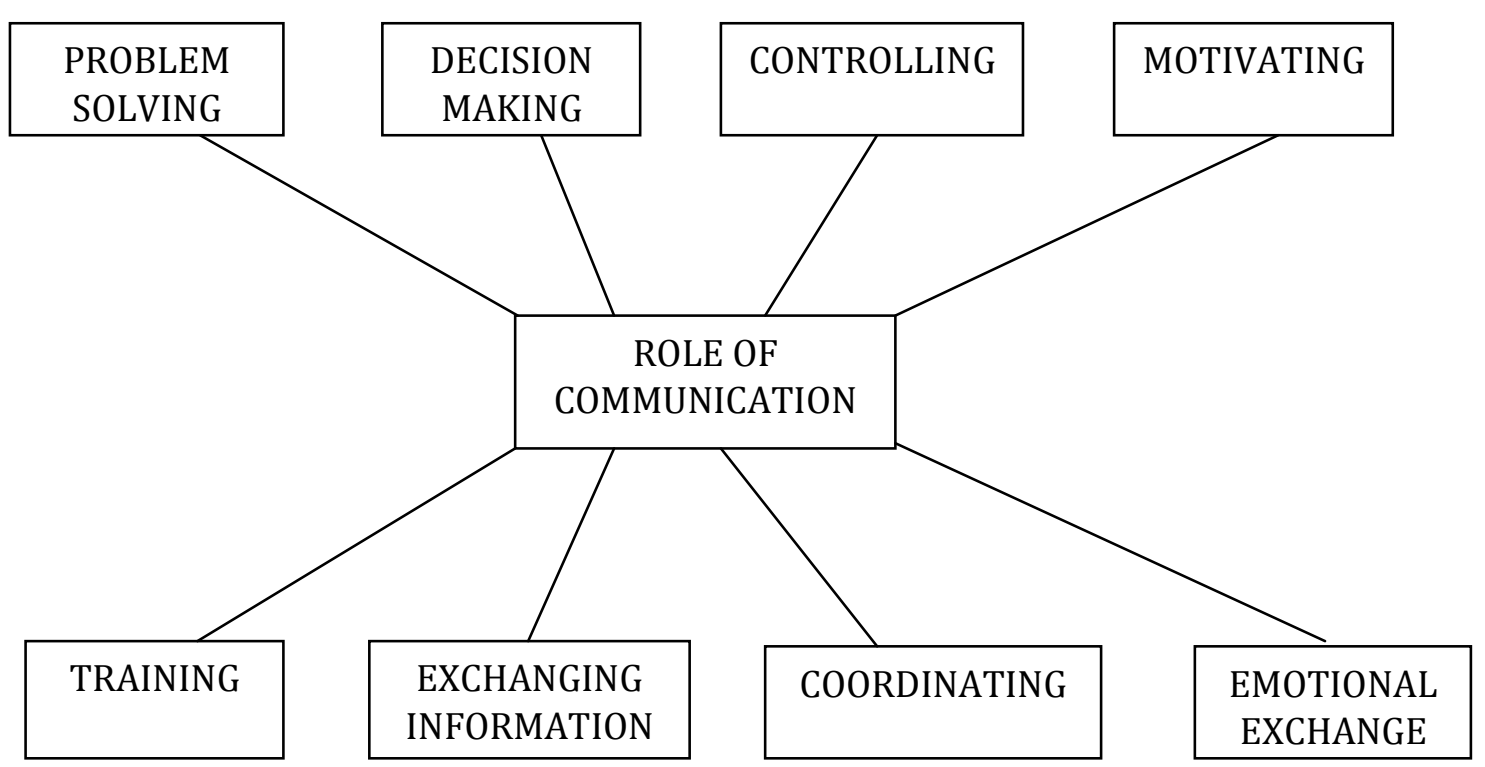

Fig: 2 Role of communication

\section{Conclusion}

There has been a splendid work done under the same title. But, this study is conducted on a practical base through observations, interviews and questionnaires. While communication in management is not always easy, one may find himself having to work with difficult people, or with unmotivated people. This gives a challenging situation to deal and gain it rather you possess expertise in communication. Expressing you well and understanding others well are the almost all job that is done in an organization. Moreover, the study has reached its objective by recognizing effective communication and good communication skills as the instruments of professional excellence. The study will be helpful to those who are new comers and willing to gain professional height. It will serve them as a helping tool moving towards their set destination.

\section{References}

1. Heath \& Bryant, (2000), "Human Communication Theory and Research: Concepts, Contexts, and Challenges" (Routledge Communication Series) 2nd edition

2. Katz D \& Kahn R L (1966). “The social psychology of organizations”. New York: Wiley

3. Poole, (1978, p. 493), "An information-task approach to organizational communication".

4. Farace, Monge and Russell (1977), "The systems perspective as a theoretical basis for the study of human communication".

5. Shockley-Zalabak, (1999, p. 28), "Trust in top management: the relationship to satisfaction, perceived organizational effectiveness and information receiving". 
6. (Shockley-Zalabak, (1999), "Trust in top management: the relationship to satisfaction, perceived organizational effectiveness and information receiving".

7. Hybels and Weaver (1995),"An exploration of communication problems among Thai vendors and foreigners at Khaosn Road".

8. Richard Fiordo (1990),Book: Communication in education.

9. Hybels and Weaver (1995), "An exploration of communication problems among Thai vendors and foreigners at Khaosn Road". 